\title{
BIODIVERSIDAD AFIDOLÓGICA (HOMÓPTERA: APHIDIDAE) EN LAS ÁREAS CULTIVADAS DE LA CUENCA BAJA DEL RÍO LURÍN *
}

\author{
MENANDROS. ORTIZ \\ Facultad de Ciencias Biológicas, Universidad Ricardo Palma \\ Apartado 138 Lima - Perú \\ E-mail: mortiz@li.urp.edu.pe
}

RESUMEN

En base a colecciones efectuadas principalmente sobre cultivos ubicados en el área de estudio se han logrado identificar las siguientes especies de áfidos: Aphis gosypii Glover, Hyadaphis pseudobrassicae (Davis), Hyperomyzus lactucae (Linnaeus), Macrosiphum avenae (Fabricius), M. euphorbiae (Thomas), M. rosae (Linnaeus), Myzus persicae (Sulzer) y Rhopalosiphum maidis (Fitch). Se presentan los caracteres morfológicos de identificación, así como algunos comentarios de importancia. Todas las especies constituyen nuevos registros para la zona estudiada.

Palabras Claves: Afidos, Pulgones, Aphididae.

\section{SUMMARY}

Proceeding of crops at studied area are identified the following species of aphids: Aphis gosypii Glover, Hyadaphis pseudobrassicae (Davis), Hyperomyzus lactucae (Linnaeus), Macrosiphum avenae (Fbricius), M. euphorbiae (Thomas), M. rosae (Linnaeus), Myzus persicae (Sulzer), y Rhopalosiphum maidis (Fitch). Morphological characteristic and some important comments are presented. All the species are new records, for zone of studies.

Key Words: Aphids, Aphididae.

\section{INTRODUCCIÓN}

Los áfidos, conocidos también como pulgones constituyen un interesante grupo de insectos de gran importancia económica. Se presentan por lo general en colonias, ubicándose preferentemente en el envés de las hojas; sin embargo también es posible hallarlos en otros órganos de las plantas hospederas, como lo son las flores. Son insectos pequeños con cuerpo suave y globoso de aspecto piriforme. Las poblaciones de especies que ocurren en el neotrópico están conformadas por formas aladas y ápteras. Todas son hembras partenogenéticas y vivíparas. El daño directo que ocasionan a las plantas cultivadas está dado por su comportamiento alimenticio con la ayuda de sus piezas bucales picadoras chupadoras. Este hecho está a la vez relacionado con la transmisión de virus fitopatógenos, los que ocasionan diversas enfermedades a las plantas; constituyendo ello los daños de tipo indirecto. Por otro lado, la melaza excretada a través del ano sobre las hojas, sirve de sustrato para el crecimiento y desarrollo del hongo negro conocido como fumagina, impidiendo de esta manera la función fotosintética de la planta.

Por las razones antes expuestas, y por la necesidad de conocer correctamente la composición de las especies de este grupo de insectos, es necesario efectuar este tipo de trabajo. que indudablemente servirá siempre de base para realizar otros trabajos como los relacionados con el control biológico así como a la transmisión de virus.

\section{ANTECEDENTES}

En nuestro país no son muchos los trabajos sobre sistemática de insectos y particularmente sobre los áfidos, el hecho se plantea sin variación a pesar de la importancia que presentan. Los trabajos que datan desde la década de los 30 hasta aproximadamente los años 70 han sido siempre dentro del contexto de importancia agronómica, habiendo en algunos casos una denominación incorrecta de las especies. Posteriormente surgieron algunos trabajos que tratan sobre aspectos taxonómicos de áfidos.

Es así que, los primeros trabajos de índole agronómico fueron los de Wolcott (1928) y el de Townsend (1939), tratando a especies de áfidos que se comportan como plagas del algodonero y caña de azúcar. Más adelante Wille $(1943,1952)$ cita especies adicionales de pulgones, pero siempre dentro del contexto agronómico.

Smith $(1971 \mathrm{a}, \mathrm{b})$ practicamente inicia los trabajos sobre áfidos desde un punto de vista taxonómico, publicando sendas listas de especies, teniendo en cuenta a diversas especies de plantas hospederas, entre las que se encuentran cultivadas y silvestres. Ortiz $(1972,1973,1974)$ presenta del mismo modo inventarios de especies con nuevos registros para el país. Es importante resaltar también el trabajo de Valencia et al. (1975) quienes trabajaron con especies provenientes de la sierra central. Del mismo modo Ortiz et al. (1981) trabajaron con especies de importancia en el cultivo de cebada en tres zonas diferentes del país. Igualmente debe citarse los trabajos de Rubín de Celis y Ortiz (1994) y el de León y Ortiz (1995) quienes registraron una serie de especies procedentes de diferentes plantas hospederas, contribuyendo de esta manera al conocimiento de este importante grupo de insectos. 


\section{MATERIALESYMÉTODOS}

Los ejemplares de áfidos observados provienen de la cuenca baja del río Lurín, correspondiendo esta zona al distrito de Pachacamac. Fueron colectados y preservados, tanto las formas aladas como las ápteras y los estados ninfales en tubo (vials) conteniendo alcohol al $70 \%$, etiquetadas con datos de campo. De este material se seleccionó una parte, para el montaje en láminas de microscopía, de modo que sirvieran para la respectiva identificación.

\section{RESULTADOS}

\section{Aphis gossypii Glover}

La hembra vivípara alada presenta una longitud que varía entre 1.48 a $1.86 \mathrm{~mm}$. El color que presenta el abdomen varía de verde-amarillento a verde oscuro. En ejemplares montados en láminas de microscopía se observa un color pardo oscuro en la cabeza y antenas, tórax, cornículos y cauda y algunas manchas sobre los lados y dorso del abdomen, placa genital, anal, coxas, fémures medios y posteriores, extremos de las tibias y todos los tarsi. Las antenas son de menor longitud que el cuerpo y presenta de 4 a 10 sensorios secundarios sobre el segmento III. La cauda es triangular alargada y ligeramente constricta en la parte media y porta 2 a 3 pares de setas laterales. Los cornículos presentan superficie imbricada y son ligeramente más largos que la cauda. El extremo del rostrum no alcanza las mesocoxas. La forma áptera es similar a la alada en coloración; sin embargo, en los ejemplares montados se observa menores marcas oscuras.

Como se observa, es una especie que varía notablemente en el color que presenta: así como las pocas setas que presenta en la cauda, y los pocos sensorios secundarios sobre el segmento antenal III de la hembra vivípara alada.

Se trata de una especie cosmopolita, registrada en más de un centenar de plantas hospederas. En nuestro medio está considerada como una seria plaga en diversas plantas cultivadas, particularmente en el algodonero y la papa.

Material Examinado.- 56 aladas, 104 ápteras y numerosos estados ninfales en el envés de las hojas de Gossypium hirsutum (algodonero) (02.viii.97; 09.viii.97; 23.viii.97 y 20.ix.97).

\section{Hyadahis pseudobrassicae (Davis)}

La forma vivípara alada varía entre 1.60 a $2.20 \mathrm{~mm}$ de longitud. El color del abdomen es verde. En ejemplares montados en láminas de microscopía se aprecia que la cabeza y antenas, tórax, cornículos y la cauda son pardooscuros. Del mismo modo lo son la placa genital, la placa anal y todas las patas, así como existen manchas sobre los aspectos laterales del abdomen. Las antenas son más cor- tas que la longitud del cuerpo y presentan de 14 a 29 sensorios secundarios sobre el segmento antenal III y sobre el IV estos varían sólo de 2 a 11. La cauda es corta, con lados paralelos, estrecha en la mitad distal y presenta 2 pares de setas laterales. Los cornículos son cortos y ligeramente dilatados distalmente; algo más largos que la cauda. El ápice del rostrum llega a un punto medio entre las coxas anteriores y medias. Las setas antenales y corporales son muy cortas y ápice algo romo. El color del abdomen de la forma áptera va del amarillo al verde.

Las principales características que distinguen a esta especie son los sensorios tuberculados sobre los segmentos antenales III y IV de la alada vípara, la cauda corta con 5 setas y los cornículos cortos y algo dilatados apicalmente.

Se trata de una especie que en nuestro medio se comporta como plaga de crucíferas, registrada también con el nombre de Lypaphis psedobrassicae.

Material Examinado.- 15 aladas, 25 ápteras y algunos estados ninfales sobre Brassica oleracea (col) (13.ix.97, 20.ix.97).

\section{Hyperomyzus lactucae (Linnaeus)}

La hembra alada vivípara mide entre 1.80 a $2.10 \mathrm{~mm}$ de longitud. Presenta una coloración verde claro, con una placa oscura sobre el dorso abdominal. En ejemplares aclarados y montados en láminas de microscopía se observan oscuros las siguientes partes: cabeza y antenas, tórax, ápices femorales, tibias, tarsi y extremo apical de los cornículos, aunque excepcionalmente estas estructuras puedan ser oscurecidas. Presenta un esclerito en la parte posterior de los cornículos y otro pequeño en la parte anterior. Igualmente presenta escleritos en los márgenes abdominales y el dorso del mismo presenta una placa rectangular oscura. El segmento antenal III presenta de 40 a 52 sensorios secundarios, y en los segmentos antenales IV y V estos varían entre 10 a 18 y 0 a 8 , respectivamente. La cauda presenta 3 pares de setas laterales. Los cornículos son algo dilatados en la parte media, para luego adelgazarse. La hembra áptera vivípara es de color similar.

Entre los caracteres diferenciales de mayor importancia se señala los numerosos sensorios secundarios de aspecto tuberculado que presenta la hembra alada vivípara sobre los segmentos antenales III, IV y V y la placa dorsal oscura sobre el dorso del abdomen. La hembra áptera vivípara presenta también sensorios secundarios sobre el segmento antenal III, los que varían entre 6 a 12. Además presenta un proceso rectangular sobre el vertex de la cabeza.

Esta especie es usual hallarla sobre la cerraja, especies del género Sonchus, eventualmente compartiendo hospederos con Uroleucon sonchi.

Material Examinado.- 6 aladas y 18 ápteras sobre Sonchus oleraceus (02.viii.97 y 20.ix.97). 


\section{Macrosiphum avenae (Fabricius)}

La hembra alada vivípara llega a medir entre 2.30 a 3.0 $\mathrm{mm}$ de longitud. El color del abdomen es verde. En ejemplares montados y aclarados se notan que son pardo negruzcas a negras las antenas, el pterotorax, los cornículos, los ápices de los fémures, los ápices de las tibias y todos los tarsi. Igualmente se observan manchas en los aspectos laterales y dorso-laterales del abdomen y en el extremo del rostrum. Las antenas son casi tan largas como la longitud del cuerpo y presenta de 7 a 17 sensorios secundarios sobre el segmento antenal III. La cauda es relativamente corta, delgada, espatulada y porta de 3 a 4 pares de setas laterales y 16 2 setas dorsales preapicales. Los cornículos se adelgazan hacia el extremo posterior; de superficie ligeramente imbricada en los dos tercios proximales y reticulada en el tercio distal; de mayor longitud que la cauda. El rostrum es corto y alcanza a una superficie ubicada entre las coxas anteriores y las coxas medias. Las setas de las antenas y del cuerpo son cortas y algo romas. La hembra vivípara áptera presenta el color del abdomen de modo similar y en el segmento antenal III porta 1 ó 2 sensorios secundarios.

Se trata de una especie oligófaga que prefiere hospederos de las gramíneas, entre las que se encuentran la cebada, trigo, maíz, etc. Entre las características de importancia resaltan los cornículos cortos y negros y el área reticulada en el tercio distal. La cauda corta y espatulada, también constituye un carácter importante.

Material Examinado.- 5 aladas y 7 ápteras sobre Zea mays (13.ix.97 y 20.ix.97).

\section{Macrosiphum euphorbiae (Thomas)}

La hembra vivípara alada mide entre 2.50 a $3.45 \mathrm{~mm}$ de longitud. El color del abdomen es ligeramente verde pudiendo llegar también a tonos rosados. En ejemplares montados en láminas de microscopía presentan color pardo oscuro las siguientes partes: segmento antenal III, excepto la base, segmentos antenales IV a VI, mitad distal de los cornículos, extremo distal del rostrum, ápices de los fémures y las tibias y todos los tarsi. La antena es más corta que el cuerpo y presenta de 11 a 18 sensorios secundarios sobre el segmento antenal III. La cauda es larga, adelgazándose hacia el extremo y sin notable constricción; porta 4 a 5 pares de setas laterales y 1 ó 2 setas dorsales preapicales. Los cornículos son largos, tendiendo a ser delgados hacia el extremo distal, de superficie imbricada, excepto por el décimo distal que es reticulado; y es casi el doble de longitud que la cauda. El rostrum no alcanza las coxas medias. Las setas de las antenas y del cuerpo son cortas y ligeramente capitadas. La hembra vivípara áptera es similar en coloración y presenta de 2 a 5 sensorios secundarios sobre el segmento antenal III.

Se trata de una especie distribuida en todo el mundo, cuyos caracteres principales son la longitud del área reticulada de los cornículos; la longitud y forma de la cauda y el número de setas que presenta, así como el número de sensorios secundarios sobre el segmento antenal III.

Blackman \& Eastop (1985) la refieren como una especie altamente polífaga, presentando alrededor de 200 hospederos, entre las que destacan fundamentalmente las solanáceas, señalando igualmente que es responsable de la transmisión de una serie de virus persistentes y no persistentes.

Material Examinado.- 28 aladas, 45 ápteras y regular número de ninfas, sobre Ipomoea batatas (16.viii.97; 23.viii.97 y 06.ix.97), Hibiscus rosa-sinensis (16.viii.97); Geranium sp. (06.ix.97).

\section{Macrosiphum rosae (Linnaeus)}

La hembra alada vivípara mide entre 3.1 a $3.8 \mathrm{~mm}$ de longitud. El color del abdomen es ligeramente verde, existiendo formas con color ambar hasta el rosado. En ejemplares montados y aclarados se observan las siguientes partes de color oscuro: la cabeza y las antenas, tórax, cornículos, ápices femorales, bases, ápices tibiales y los tarsi. De igual manera se observan manchas oscuras sobre los aspectos laterales del abdomen, siendo aquellas del dorso más pequeñas. Son algo oscuros el ápice del rostrum, la placa genital y la placa anal. La cauda es pálida y porta 5 pares de setas laterales y 2 setas dorsales pre-apicales. Los cornículos son largos, cilíndricos, ligeramente anchos basalmente y constrictos cerca del extremo apical; de superficie imbricada, excepto por la reticulación en el décimo distal. El ápice del rostrum no alcanza las coxas medias. Las setas antenales y corporales son cortas y algo romas. La hembra áptera vivípara es semejante en coloración y presenta de 16 a 21 sensorios secundarios sobre el segmento antenal III. El ápice del rostrum sobrepasa las coxas medias.

Entre los caracteres que destacan figuran los apéndices negros, la cauda pálida, la longitud y forma de los cornículos y los numerosos sensorios secundarios sobre el segmento antenal III (Kono y Papp, 1977)

Es una especie que se encuentra ampliamente distribuidos sobre las rosas, en donde se comporta como plaga. De tal manera la obervaron Rubín de Celis y Ortiz (1994) con altísimas poblaciones en la provincia de Canta, resultando en aquella oportunidad la especie más difundida, por lo que incluso se le observó sobre otros hospederos de manera forzada.

Material Examinado.- 8 aladas , 27 ápteras y un reducido número de estados ninfales (02.viii.97 y 16.viii.97).

\section{Myzus persicae (Sulzer)}

La hembra vivípara alada tiene una longitud que oscila entre 1.95 a $2.40 \mathrm{~mm}$. El color del abdomen es verdeamarillento con placas oscuras sobre el dorso. En ejemplares aclarados y montados en láminas de microscopía 
se observan las siguientes áreas de color pardo oscuro: la cabeza y las antenas, excepto la base del segmento III, tórax, cornículos, cauda y placas sobre los lados y dorso del abdomen, coxas, ápices femorales, tibias, tarsi, placa genital y placa anal. La cauda es ligeramente constricta en la parte media y porta 3 pares de setas laterales. Los cornículos son cilíndricos y distalmente son ligeramente dilatados. Presenta una doble longitud comparada con la cauda. El ápice del rostrum no alcanza las coxas medias. Las setas corporales son cortas y ligeramente capitadas. La hembra áptera vivípara varía entre 1.60 a $2.30 \mathrm{~mm}$ de longitud; presenta una coloración amarilla pálida a verde.

Se trata de una especie cosmopolita de gran importancia agrícola y con un amplio rango de hospederos. Entre los caracteres de importancia se distinguen el color verde pálido, la placa dorsal oscura sobre el abdomen, el número de sensorios secundarios sobre el segmento antenal III de la hembra vivípara alada y la forma de los cornículos.

Es posible encontrarla compartiendo el hospedero con algunas otras especies, de conformidad a lo observado por León y Ortiz (1995). Raman (1985) la considera como el principal vector de virosis en papa, tanto de virus persistentes como no persistentes, destacando el PLRV (virus del enrrollamiento de la hoja de la papa).

Material Examinado.- 54 aladas, 128 ápteras y numerosos estados ninfales sobre Ipomoea batatas, Amaranthus dubius y Apium graveolens (02.viii.97, 13.ix.97).

\section{Rhopalosiphum maidis (Fitch)}

La hembra vivípara alada mide entre 1.80 a $2.10 \mathrm{~mm}$ de longitud. El color del abdomen es verde. En ejemplares aclarados y montados en láminas de microscopía las siguientes áreas son de color pardo oscuro: la cabeza y las antenas, tórax, cornículos, cauda, placa genital y placa anal, manchas sobre los aspectos laterales del abdomen. La antena es más corta que la longitud del cuerpo y presenta de 14 a 23 sensorios secundarios sobre el segmento antenal III, del mismo modo en los segmentos antenales IV y $\mathrm{V}$, presenta de 0 a 8 y de 0 a 3 sensorios secundarios, respectivamente. La base del segmento antenal VI es aproximadamente la mitad de la longitud del unguis. La cauda es espatulada y porta 2 ó 3 pares de setas laterales. Los cornículos son ligeramente dilatados en la parte media y con superficie imbricada y éstas a su vez son ligeramente aserradas. El ápice del rostrum no alcanza las coxas medias. Las setas antenales y corporales son cortas y agudas. La hembra vivípara áptera mide entre 1.60 a 2.20 $\mathrm{mm}$ de longitud. Es similar a la forma alada en coloración.

Esta especie es oligófaga y habita sobre maíz, trigo, cebada, sorgo y otros hospederos similares. De manera similar la cita Ortiz (1972), pudiendosele encontrar compartiendo el hospedero con $\boldsymbol{R}$. padi (Linnaeus) de acuerdo a las observaciones de León y Ortiz (1995). Se le distingue principalmente por la forma de la cauda y el número de setas que presenta, así como por el número de sensorios secundarios de los segmentos antenales III, IV y V.

Material Examinado.- 38 aladas, 75 ápteras y numerosos estados ninfales sobre Zea mays (23.viii.97, 13.ix.97 y 20.ix.97).

\section{REFERENCIAS BIBLIOGRÁFICAS}

BLACKMAN, R.L. AND V.F. EASTOP. 1985. Aphids on the World's Crops: An Identification Guide. Jojn Willey \& Sons. England, $466 \mathrm{pp}$.

KONO, T. AND CH. PAPP. 1977. Handbook of Agriculture Pest Aphids. Thrips, Mites, Snails, and Slugs. Department od Food and Agriculture, California, $205 \mathrm{pp}$.

LEÓN, C.L. Y M.S. ORTIZ. 1995. Afidos (Homoptera: Aphididae) del Valle de Cañete (Lima-Perú). Biotempo 2: 107 113.

ORTIZ, M.S. 1972. Notas sobre algunas especies de áfidos del Perú. Resúmenes de la XV Convención Nacional de Entomología, Ica, Perú. 87 pp.

ORTIZ, M.S. 1973. Rhopalosiphoninus latysiphon (Davidson) un áfido de sifones peculiares. Rev. Per. Ent. 16: 125-126.

ORTIZ. M. S. 1974. Hallazgo de un macho de Myzus persicae (Sulzer). Rev. Per. Ent. 17: 127-128.

ORTIZ. M. S., A. Rodríguez y J. Sarmiento. 1981. Los Afidos (Homoptera: Aphididae) de la Cebada (Hordeum vulgare) en la Sierra y Costa Central del Perú. Rev. Per. Ent. 24: 133-136.
RAMAN, K.V. 1985. Estudios de Poblaciones de Afidos. Cen tro Internacional de la Papa (CIP). Serie IV, 2, 12 pp.

RUBÍN DE CELIS, V.E. Y M.S. ORTIZ. 1994. Aphididae (Insecta: Homoptera) procedentes de Canta (Lima-Perú). Biotempo 1: 39-42.

SMITH, C.F. 1971a. Survey of aphids on potatoes and beans in Peru with notes on the other plants. First Report, North Carolina State University, $11 \mathrm{pp}$.

SMITH, C.F. 1971b. Survey on aphids on potatoes in Peru with notes on aphids on the other plants. Second Report, North Carolina State Unversity, $31 \mathrm{pp}$.

VALENCIA, L., C, GUERRA Y F. GUTARRA. 1975. Los áfidos (Homoptera: Aphididae) del Valle del Mantaro, plantas hospederas y enemigos naturales. Rev. Per. Ent.18: 90-97.

WILLE, J.E. 1943. Entomología Agrícola del Perú. Ministerio de Agricultura. Primera Edición, Lima-Perú, 543 pp.

WILLE, J.E. 1952. Entomología Agrícola del Perú. Ministerio de Agricultura. Segunda Edición, Lima-Perú, 543 pp.

WOLCOTT, G.E. 1928. Los afidos que afectan la industria azucarera del Perú. Estación Experimental Agrícola La Molina, Lima-Perú, Circ. 12: 1-11. 